\title{
Offshore Wind Energy and the Romanian Energy Future
}

\author{
Florin Onea* and Liliana Rusu \\ Department of Mechanical Engineering, "Dunarea de Jos"' University of Galati, Domneasca Street, 47, Galati 800008, Romania
}

\begin{abstract}
The aim of the present work is to assess the electricity production coming from an offshore wind farm that may operate in the northern part of the Romanian coastal area. In the first part, a complete description of the Romanian energy sector is presented considering the time interval from January 2008 to December 2018. In general, the electricity sold is negative (exports exceed imports), with the mention that a significant contribution comes from hydroelectric and coal generation. It is important to mention that, if one of these two sectors will no longer perform on full capacity, the electricity balance will be shifted to the electricity imports. As for the wind energy, the average values from the vicinity of Sulina site may vary between $5.6 \mathrm{~m} / \mathrm{s}$ and $8 \mathrm{~m} / \mathrm{s}$ depending on the season, these results being reported at a wind turbine level $(80 \mathrm{~m})$. By using an offshore wind farm which replicates the Greater Gabbard project (504 MW), England, was possible to estimate the annual energy production and to indicate the expected impact on the energy sector. For example, a single wind farm may cover $1.7 \%$ of the total production, which may be further associated with $9.6 \%$ from nuclear, $7.6 \%$ from hydroelectric or $6.4 \%$ from coal, respectively.
\end{abstract}

\section{Introduction}

The renewable energy sources represent an important part of any energy market, being possible at this moment to implement smart energy systems in order to develop a sustainable future [1]. The countries located near the coastal areas may expand the energy portfolio, by adding some particular natural source, such as the offshore wind or waves. By looking on Europe map, we can see that most of the countries are defined by marine areas capable to support renewable marine projects $[2,3]$.

Romania is located in such region, being defined by $245 \mathrm{~km}$ of coastline facing the north-western part of the Black Sea. Compared to some other renewable sources, the evolution of onshore wind is visible, starting from 1.32 MW in 2005 and being expected a $4000 \mathrm{MW}$ for the year 2020. The hydropower sector may increase from $6289 \mathrm{MW}$ (2005) to $7729 \mathrm{MW}$ (2020), while in the case of photovoltaic and biomass a cumulated value of 860 MW is predicted for 2020 [4]. Regarding the electricity coming from fossil fuels, more precisely from coal production, we can see that as in any other countries, the Romanian electricity market is heavily supported by this sector. Romania is a major coal producer, being included in a Top 6 producers from the EU countries and in a Top 25 reported on a global scale [5]. The impact of the restructuring measurements performed in the mining sector in 2012, w more visible in 2016 when the production was reduced with almost $39 \%$ and $49 \%$ in the case of the lignite and bituminous coal, respectively.

Nevertheless, during the last years, this market was more stable being possible to report some exports, which was estimated to be around $2 \%$ from the entire production [5].
Another important source of electricity comes from the hydropower plants, which are defined by total capacity of $6443 \mathrm{MW}$ reported for the year 2015. As expected, this sector is significantly influenced by the presence of dry season, being reported events when the mu ltiannual average flow rate may fall from $1226 \mathrm{~m}^{3} / \mathrm{s}$ to almost $679 \mathrm{~m}^{3} / \mathrm{s}$ (the dry year 1990) [6].

During the recent years, a significant amount of work was dedicated to the assessment of the wind conditions from the Black Sea basin. A complete description of these resources is presented in Ganea et al [7], which also cover the interval from 2021 to 2050 . Th is is also the case of Rusu et al [8] where a hindcast database was considered for investigation. In Onea and Rusu [9], the performances of some state-of-the-art wind turbines that may operate near the Black Sea coasts were estimated. A full spectrum of systems was considered, starting from a $3 \mathrm{MW}$ device and ending with a 9.5 MW system. The efficiency of some wind turbines was discussed in Onea and Rusu [10], where a special attention was given to the diurnal and nocturnal fluctuations of the wind resources. Rusu et al [11] carried out a joint evaluation of the wind and wave resources, the emphasis being put on the main shipping routes that cross this region. From these results, it is clear that the western part of the Black Sea reveals more important wind resources, this area being also defined by a continental shelf.

As for the Romanian coastal environment, previous studies suggest that the northern part of this region show more significant wind resources $[12,13]$. The operational onshore wind farm Fantanele/Cogealac is located near to this region, being considered to be one of the largest project from Europe with $600 \mathrm{MW}$ [14].

\footnotetext{
* Corresponding author: florin.onea@ugal.ro
} 


\section{Methods and materials}

For the present work, a reference site located in the northern part of the Romanian coast will be considered for evaluation, as can be noticed from Figure 1. Th is is located at approximately $23 \mathrm{~km}$ offshore for which correspond a water depth of $32 \mathrm{~m}$, all these characteristics replicating the conditions reported by the Greater Gabbard wind farm from England. A number of 140 units of SWT-3.6-107 defines this project, which is operational since 2013 [15].

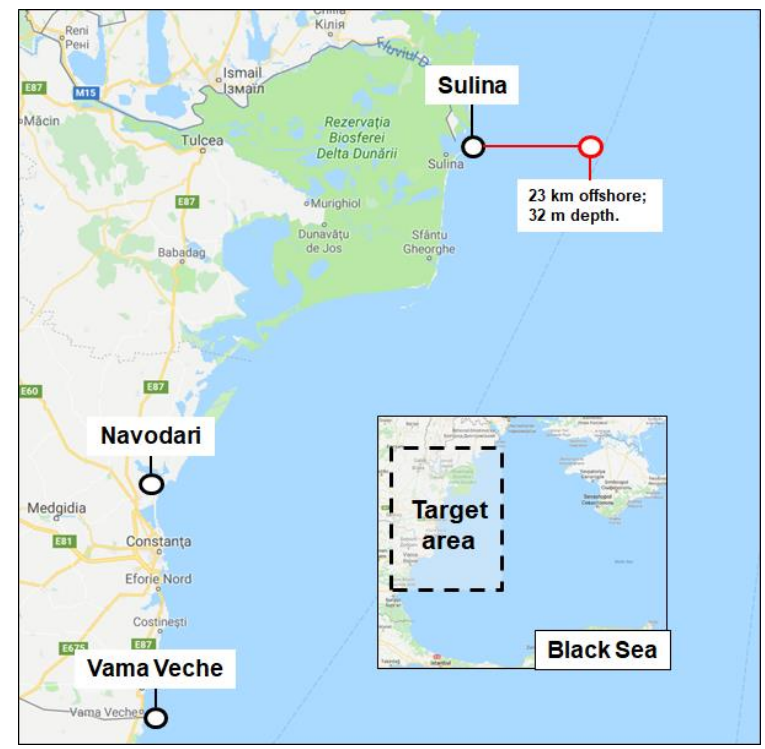

Fig. 1. The Romanian coastal area and the Sulina site considered for assessment.

More details regarding the SWT-3.6-107 model are presented in Table 1 [16], and based on these values was proposed a case study.

Table 1. Characteristics of the SWT $-3.6-107$ wind turbine.

\begin{tabular}{|c|c|c|}
\hline SWT-3.6-107 & Specifications & Case study \\
\hline Nominal Power & $3.6 \mathrm{MW}$ & $3.6 \mathrm{MW}$ \\
\hline Hub heights & $80 \mathrm{~m}$ or site-specific & $80 \mathrm{~m}$ \\
\hline Cut-in wind speed & $3-5 \mathrm{~m} / \mathrm{s}$ & $4 \mathrm{~m} / \mathrm{s}$ \\
\hline Nominal power at & $13-14 \mathrm{~m} / \mathrm{s}$ & $13.5 \mathrm{~m} / \mathrm{s}$ \\
\hline Cut-out wind speed & $25 \mathrm{~m} / \mathrm{s}$ & $25 \mathrm{~m} / \mathrm{s}$ \\
\hline
\end{tabular}

The wind data processed in this work are related to the ERA-Interim dataset, that is assembled at the European Centre for Medium-Range Weather Forecasts (ECMWF) [17]. These values cover the time interval from January 1999 to December 2017 (19 years), being defined by a spatial resolution of $0.125^{\circ} \times 0.125^{\circ}$ and a temporal resolution of 6 hours $(4$ values per day corresponding to $00-06-12-18$ UTC, respectively). The wind conditions from this dataset are computed at a height of $10 \mathrm{~m}(U 10)$ above sea level.

The main focus of the present work is to assess the expected electricity production of the SWT-3.6-107 wind turbine which operates at a minimum hub height of $80 \mathrm{~m}$, an therefore the initial wind values (U10) will be adjusted to this height (U80) by using the following logarithmic law $[18,19]$ :

$$
U 80=U 10 \frac{\ln \left(z_{80}\right)-\ln \left(z_{10}\right)}{\ln \left(z_{10}\right)-\ln \left(z_{0}\right)}
$$

where, $U 80$ - wind speed at $80 \mathrm{~m}, U 10$ - initial wind speed (at $10 \mathrm{~m}), z_{0}$ - roughness of the sea surface $(0.0002 \mathrm{~m}), z_{10}$ and $z_{80}$ - reference heights.

The Annual Electricity Production $(A E P)$ of a particular wind turbine can be obtained as [15]:

$$
A E P=T \times \int_{\text {cut-in }}^{\text {cut-out }} f(u) P(u) d u
$$

where, $A E P$ is in MWh, $T$ - average hours per year (8760), $f(u)$ - Weibull probability density function, $P(u)-$ turbine power curve. The cut-in and cut-out values define the operational limits of a wind turbine, being mentioned in Table 1.

The literature review shows that the project Greater Gabbard generated in 2013 an annual net output of 1800 GWh [20]. We have estimated the performances of this wind farm $(140 \mathrm{x}$ SWT-3.6-107) for the Greater Gabbard site, by using the ERA-Interim values (U80) reported for the year 2013. When comparing our result $(1792.85 \mathrm{GWh})$ with the reported one, we may notice that the differences are very small $(0.004 \%)$, which indicate that the results expected for the Sulina sites are solid enough.

\section{Results}

In the first part of this section is evaluated the Romanian electricity system, by considering the values reported by the national energy portal [21]. This info cover the interval from January 2008 - present, being reported for the entire energy sector, and the temporal resolution of this data being close to 10 minutes.

In order to reveal the main trends, in Figure 2 was represented the evolution of the annual electricity production (average values) for each production sector, by considering the values reported between January 2008 and December 2018. In general, the electricity production is located in the range of $57960 \mathrm{GWh}$ and $64550 \mathrm{GWh}$, more consistent values being reported for the interval 2014-2018. This energetic sector is mainly supported by the contribution coming from the coal, hydroelectric and nuclear sectors. 


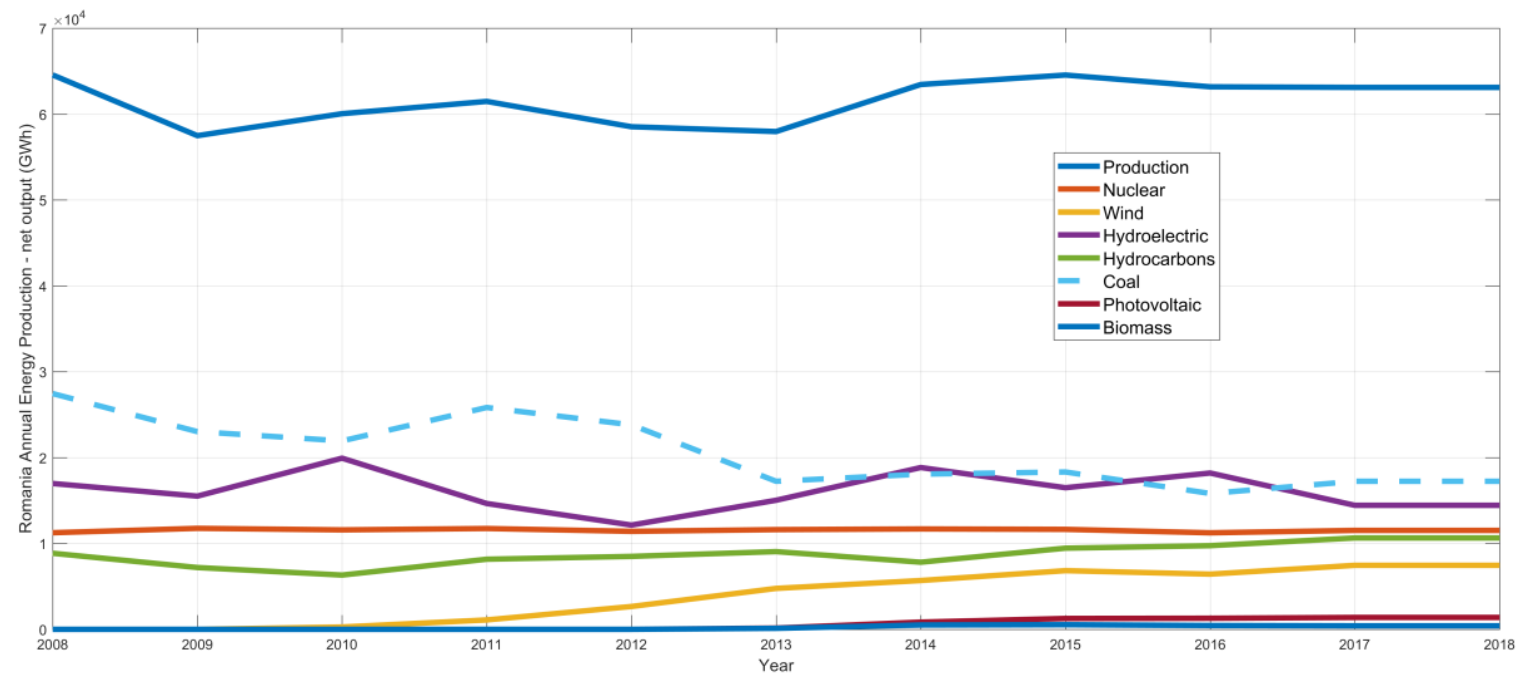

Fig. 2. Annual energy production (average values $-\mathrm{GWh}$ ) reported in terms of production and for the main energy sectors.

Compared to the nuclear production which is relatively constant (mean value $\approx 11542 \mathrm{GWh}$ ), the other two sectors present significant fluctuations. For the interval 2014 and 2016, the coal and hydroelectric sectors reported similar values. The onshore wind energy have a maximum production of 7453 GWh (for 2018), while the photovoltaic and biomass sectors reveal the lowest impact on the total electricity production.

The evolution of the electricity sold is presented in Figure 3 and Table 2 (average values), being also included a short time interval from December 2018 to January 2019.

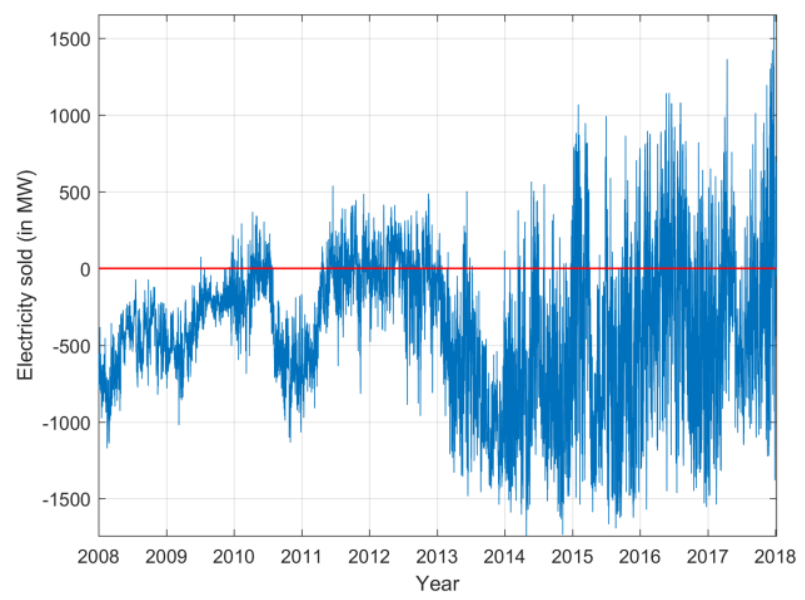

Fig. 3. Romanian electricity sold (in $\mathrm{MW}$ ) reported for the interval 2008-2018. The negative values reveal exports.

According to these values, Romania is exporting electricity, being reported an average of $239.18 \mathrm{MW}$ for the entire time interval. During the interval 2008-2013 the energy imports reported a minimum of 126.26 MW, this value significantly increased in the next years reaching an average of 362.72 MW during 2014-2018. However, according to the values reported during the latest two months, December 2018 and January 2019, we may notice that this pattern is severely changed, the balance being shifted to imports (390 MW). The main reason for this change is that during this interval, a significant percentage of the Romanian miners working at the Oltenia Energy Complex were on strike during an entire week. It is important to mention, that this mining sector cover almost $30 \%$ of the brown coal supply used to generate electricity [22].

Table 2. Statistic of the Romanian electricity exports and imports, indicated in terms of the average values.

\begin{tabular}{|c|c|c|c|}
\hline Interval & $\begin{array}{c}\text { Exports } \\
\text { (MW) }\end{array}$ & $\begin{array}{c}\text { Imports } \\
\text { (MW) }\end{array}$ & $\begin{array}{c}\text { Sold } \\
\text { (negative values } \\
\rightarrow \text { exports) }\end{array}$ \\
\hline $2008-2018$ & 572.8 & 333.62 & -239.18 \\
\hline $2008-2013$ & 382.25 & 126.26 & -255.99 \\
\hline $2014-2018$ & 712.43 & 362.72 & -349.71 \\
\hline $\begin{array}{c}\text { Dec 2018- } \\
\text { Ian 2019 }\end{array}$ & 315.46 & 705.79 & 390.33 \\
\hline \multicolumn{2}{|c|}{ Without coal-fired } \\
power plants
\end{tabular}

In order to see what happen if the coal sector will no longer generate electricity one day, we proposed some scenarios in Table 2. According to these results, Romania will become a net importer of electricity, which on a long term will be reflected by a rising electricity price.

Go ing to the offshore wind conditions, in Table 3 are presented some statistical values reported for the total distribution and for the representative seasons, where: Spring - March, April, May; Summer - June, July, August ; Autumn - September, October, November; 
Winter - December, January, February. As expected, the wind speed (average value) is more consistent during winter, when a maximum of $8.02 \mathrm{~m} / \mathrm{s}$ may be reported. In summer, we may expect a minimum of $5.56 \mathrm{~m} / \mathrm{s}$, which is below the values reported during the spring and autumn, respectively.

The downtime index represents the time percentage during which the turbine will not generate electricity, being reported to the cut-in value of the SWT-3.6-107 wind turbine.

Table 3. Statistical analy sis of the wind conditions reported by the Sulina site, considering the ERA-Interim data corresponding to the interval 1999-2017.

\begin{tabular}{|c|c|c|c|}
\hline Season & $\begin{array}{c}\text { U80 } \\
(\mathbf{m} / \mathbf{s})\end{array}$ & $\begin{array}{c}\text { Downtime } \\
(\mathbf{\%})\end{array}$ & $\begin{array}{c}\text { Rated } \\
\text { capacity (\%) }\end{array}$ \\
\hline Winter & 8.017 & 8.703 & 6.778 \\
\hline Spring & 6.371 & 18.05 & 1.502 \\
\hline Summer & 5.564 & 23.67 & 0.758 \\
\hline Autumn & 6.932 & 15.05 & 3.167 \\
\hline $\begin{array}{c}\text { Total } \\
\text { distribution }\end{array}$ & 6.714 & 16.41 & 3.033 \\
\hline
\end{tabular}

The rated capacity is defined as the time percentage during which a wind turbine will operate on full capacity, being taken into account only the values located between the nominal wind speed and the cut-out value of the SWT-3.6-107 generator. A maximum downtime of $23.67 \%$ may be expected in summer, compared to winter where only in $8.7 \%$ percentage of the time the turbine will not operate. In winter, such turbine will obtain better performances in almost $6.77 \%$ of the time, being followed by autumn $(3.16 \%)$, spring $(1.5 \%)$ and summer $(0.76 \%)$.

A more detailed investigation of the downtime windows is presented in Figure 4, by considering the consecutive period during which the wind speed does not exceed the cut-in value. For example, sequence 1 means that during two consecutive hours (ex: 00-06) the wind speed was below cut-in, while for a sequence 2 this number was increased to three consecutive hours (ex: 0006-12). In this way, it is possible to estimate the number of suitable time windows of inactivity during which the turbine will not operate. One limitation of this evaluation is that only 4 data per day are available for evaluation. For sequence 1, all the events putted together sumalmost 56 days, which is followed by sequence 2 with 32 days and by sequence 3 with 20 days.

In Figure 5 is presented the annual energy production reported by the SWT-3.6-107 generator. This evolution is defined by significant variations, being reported a minimum of $926 \mathrm{GWh}$ (in 2011) while a maximum of $1166 \mathrm{GWh}$ was accounted by 2001 . Nevertheless, during the interval 2012-2014 a constant distribution of the values was noticed (1055 GWh).

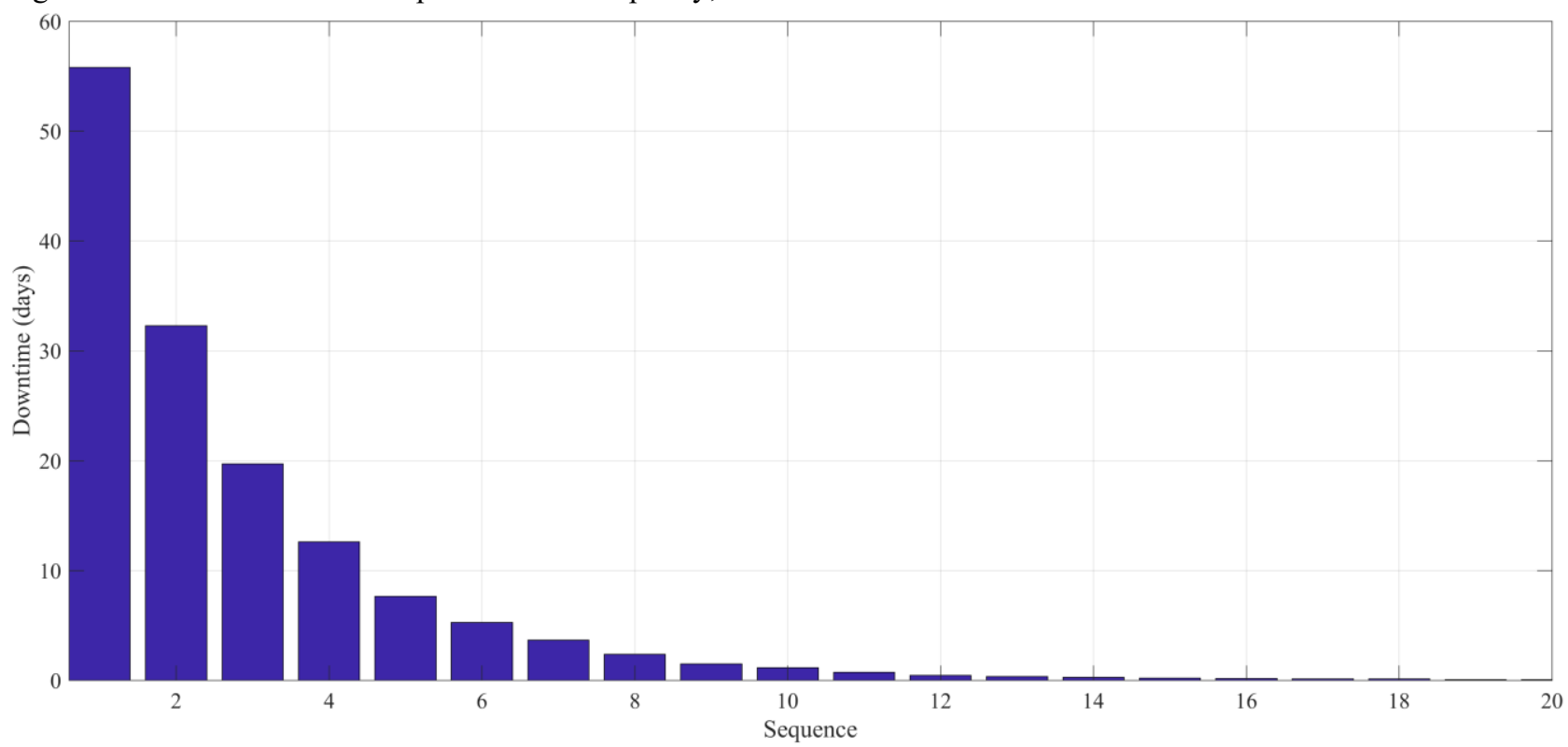

Fig. 4. Downtime sequences reported by the SWT-3.6-107 offshore wind turbine operating near the Sulina site. Results reported for the interval 1999-2017. 


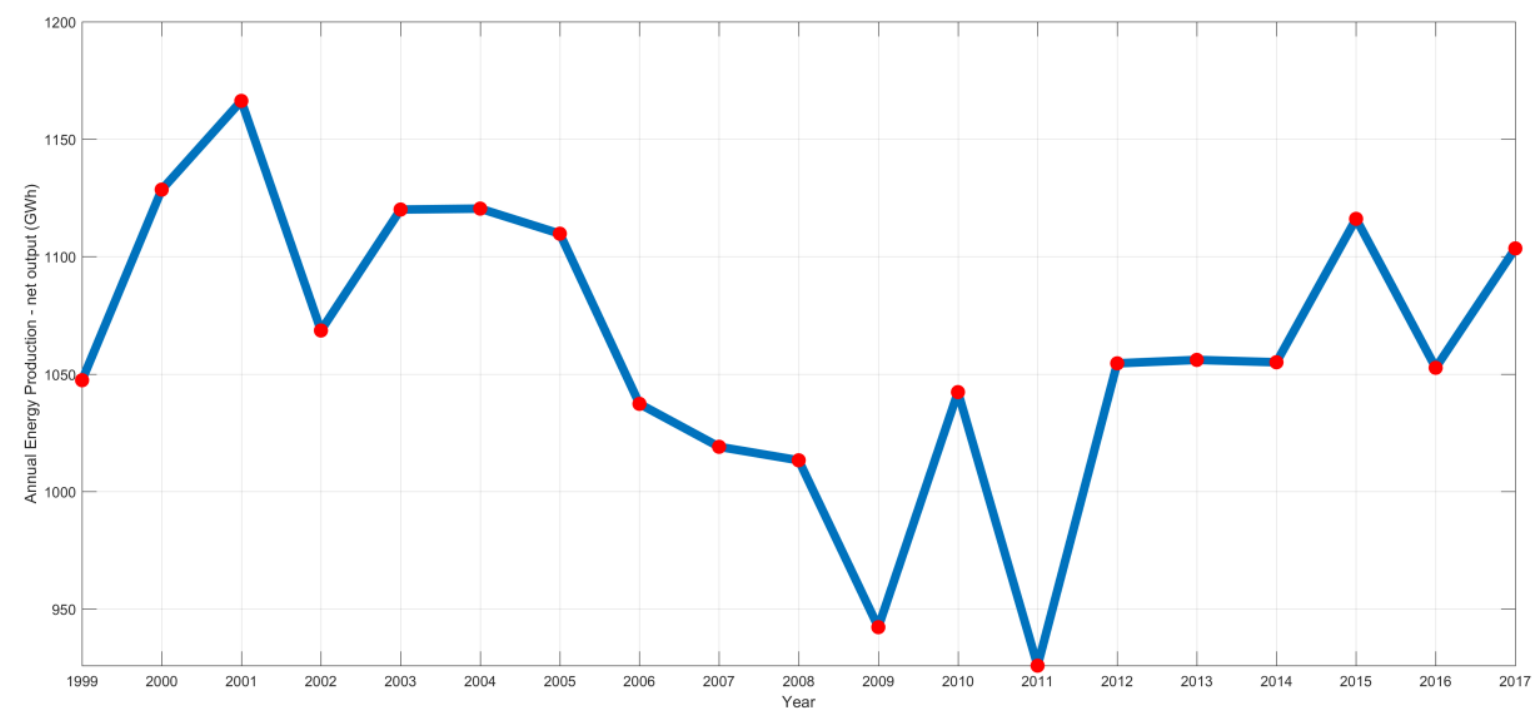

Fig. 5. Annual Energy Production (in GWh) expected from the SWT-3.6-107 wind turbines near the Sulina site.

By combining the results provided in Figure 2 and in Figure 5, was possible to identify the electricity percentage covered by an offshore wind farm that may operate in the northern part of the Romanian coastal area, these results being provided in Figure 6 .

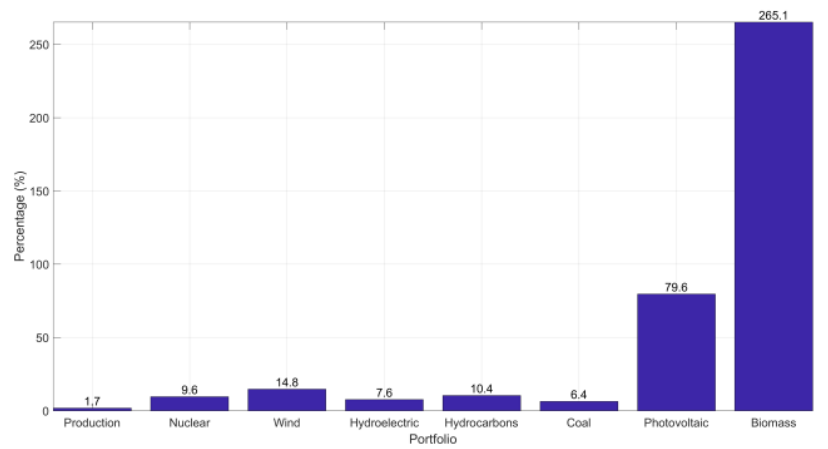

Fig. 6. The electricity share (in \%) covered by an offshore wind farm (Greater Gabbard configuration) that may operate near the Sulina site.

As we can see, a single project may cover almost $1.7 \%$ from the entire production, being possible to replace almost $10 \%$ from the energy generated from nuclear sources and close to $15 \%$ in the case of the onshore wind. For the hydroelectric and coal production, a maximum of $7.6 \%$ may be expected. The electricity coming from the photovoltaic project can be easily replaced by a single offshore wind farm, while the current biomass output is already covered.

In an ideal scenario, the electricity demand per each sector can be covered from: 10.4 projects - Nuclear; 6.8 projects - onshore wind; 13.2 projects - hydroelectric; 9.6 projects - hydrocarbons; 15.6 projects - coal or 1.3 projects - photovoltaic. The investment required for the Greater Gabbard project was close to $£ 1.6 \mathrm{bn}$, being possible to supply renewable energy to almost 530000 homes per year and creating in this way around 100 permanent jobs [23].

\section{Conclusions}

In this work, the expected benefits that may occur from the implementation of an offshore wind project near the Sulina site (Romania - north) was evaluated. Based on the electricity values reported on the national level, the fact that at this moment there is no backup plan in terms of the energy production was highlighted. If one of the main sectors (nuclear, coal or hydroelectric) will reduce their contributions, this will mean that the electric ity need will be covered from imports.

Since Romania has the possibility to develop offshore wind projects, it was considered interesting to assess the performances of a wind farm that may operate close to the Sulina site at approximately $23 \mathrm{~km}$ from the shore. Based on these results, it was noticed that a significant percentage of electricity demand can be covered throughout a such project. Many scenarios can be developed, only if we take into account that at this moment in European waters are being implemented generators defined by $8 \mathrm{MW}$ rated capacity.

\section{Acknowledgements}

This work was supported by a grant of Ministery of Research and Innovation, CNCS - UEFISCDI, project number PN-IIIP1-1.1-PD-2016-0235, within PNCDI III. The ERA-Interim data used in this study have been obtained from the ECMWF data server.

\section{References}

1. Djørup S, Thellufsen JZ, Sorknæs P. The electricity market in a renewable energy system. Energy 2018; 162:148-57. doi:10.1016/j.energy.2018.07.100.

2. Onea F, Deleanu L, Rusu L, Georgescu C. Evaluation of the wind energy potential along the Mediterranean Sea coasts. Energy Explor Exploit 2016; 34:766-92. doi:10.1177/0144598716659592. 
3. Onea F, Ciortan S, Rusu E. Assessment of the potential for developing combined wind-wave projects in the European nearshore. Energy Environ 2017; 28: 580-97. doi:10.1177/0958305X17716947.

4. Grigoras G, Scarlatache F. An assessment of the renewable energy potential using a clustering based data mining method. Case study in Romania. Energy 2015; 81: 416-29. doi:10.1016/j.energy .2014.12.054.

5. Anastasiu N, Simionescu BC, Popa ME, Mihai M, Rusu RD, Predeanu G. Romanian coal reserves and strategic trends. International Journal of Coal Geology 2018; 198:177-82. doi:10.1016/j.coal.2018.09.011.

6. Nastase G, Serban A, Nastase AF, Dragomir G, Brezeanu AI, Iordan NF. Hydropower development in Romania. A review from its beginnings to the present. Renew Sust Energ Rev 2017; 80:297-312. doi:10.1016/j.rser.2017.05.209.

7. Ganea D, Mereuta E, Rusu L. Estimation of the Near Future Wind Power Potential in the Black Sea. Energies 2018; 11:3198. doi:10.3390/en11113198.

8. Rusu L, Ganea D, Mereuta E. A joint evaluation of wave and wind energy resources in the Black Sea based on 20year hindcast information. Energy Explor Exploit 2018; 36:335-51. doi:10.1177/0144598717736389.

9. Onea F, Rusu L. Evaluation of Some State-Of-The-Art Wind Technologies in the Nearshore of the Black Sea. Energies 2018; 11:2452. doi:10.3390/en11092452.

10. Onea F, Rusu E. Efficiency assessments for some state of the art wind turbines in the coastal environments of the Black and the Caspian seas. Energy Explor Exploit 2016; 34:217-34. doi:10.1177/0144598716629872.

11. Rusu L, Raileanu AB, Onea F. A Comparative Analy sis of the Wind and Wave Climate in the Black Sea Along the Shipping Routes. Water 2018; 10:924. doi:10.3390/w10070924.

12. Onea F, Raileanu A, Rusu E. Evaluation of the Wind Energy Potential in the Coastal Environment of Two Enclosed Seas. Adv Meteorol 2015:808617. doi:10.1155/2015/808617.
13. Onea F, Rusu E. An Evaluation of the Wind Energy in the North-West of the Black Sea. Int J Green Energy 2014; 11:465-87. doi:10.1080/15435075.2013.773513.

14. Europe's biggest is online in Romania. Renewable Energy Focus 2013; 14:8. doi:10.1016/S1755-0084(13)70003-6.

15. Arrambide I, Zubia I, Madariaga A. Critical review of offshore wind turbine energy production and site potential assessment. Electric Power Systems Research 2019;167:39-47. doi:10.1016/j.epsr.2018.10.016.

16. Siemens SWT-3.6-107 - Manufacturers and turbines Online access - The Wind Power n.d. https://www.thewindpower.net/turbine_en_20_siemens_sw t-3.6-107.php (accessed January 21, 2019).

17. Dee DP, Uppala SM, Simmons AJ, Berrisford P, Poli P, Kobayashi S, et al. The ERA-Interim reanalysis: configuration and performance of the data assimilation system. Q J R Meteorol Soc 2011; 137:553-97. doi:10.1002/qj.828.

18. Rusu E, Onea F. Joint Evaluation of the Wave and Offshore Wind Energy Resources in the Developing Countries. Energies 2017; 10:1866. doi:10.3390/en10111866.

19. Onea F, Rusu E. Sustainability of the Reanalysis Databases in Predicting the Wind and Wave Power along the European Coasts. Sustainability 2018; 10:193. doi:10.3390/su10010193.

20. Greater Gabbard wind farm. Wikipedia 2018.

21. Productia si consumul de energie electrica in Romania, pe ramuri de productie n.d. http://version1.sistemulenergetic.ro/ (accessed January 22, 2019).

22. Romanian coal miners end strike after government hikes wages - The Washington Post n.d. https://www.washingtonp ost.com/world/europe/romaniancoal-miners-end-strike-after-government-hikeswages/2019/01/17/09d835ce-1a6f-11 e9-b8e6$567190 \mathrm{c} 2 \mathrm{fd} 08$ story.html?noredirect $=$ on\&utm_term $=.4 \mathrm{~b} 0$ c0af29bf3 (accessed January 22, 2019).

23. Greater Gabbard n.d. http://sse.com/whatwedo/ourp rojectsandassets/renewables/ GreaterGabbard/ (accessed January 23, 2019). 